\title{
Selectivity Control during the Single-Step Conversion of Aliphatic Carboxylic Acids to Linear Olefins
}

\author{
Jher Hau Yeap, ${ }^{\dagger}$ Florent Héroguel, ${ }^{\dagger}$ Robert L. Shahab, ${ }^{\dagger}{ }^{\ddagger}$ Bartosz Rozmysłowicz, ${ }^{\dagger}$ Michael H. Studer, ${ }^{\ddagger}$ \\ and Jeremy S. Luterbacher*, ${ }^{*}$ (1)
}

${ }^{\dagger}$ Laboratory of Sustainable and Catalytic Processing, Institute of Chemical Sciences and Engineering, École Polytechnique Fédérale de Lausanne (EPFL), CH-1015 Lausanne, Switzerland

${ }^{\ddagger}$ Laboratory of Biofuels and Biochemicals, School of Agricultural, Forest and Food Sciences, Bern University of Applied Sciences (BFH), CH-3052 Zollikofen, Switzerland

\section{Supporting Information}

ABSTRACT: We have studied the single-step catalytic conversion of biomass-derived aliphatic carboxylic acids to linear olefins via tandem hydrogenation/dehydration reactions. Hexanoic acid was converted to a mixture of hexenes $(92.0 \%$ selectivity) over silica-alumina supported $\mathrm{Cu}$ nanoparticles. Remarkably, we observed a rapid selectivity switch to $99.8 \%$ hexane once carboxylic acids were fully consumed, with similar results using butanoic acid derived from biomass using consolidated bioprocessing. Based on intermediate, desorption, and in situ spectroscopy studies, we propose that the presence of a small amount of carboxylic acid on the catalyst surface leads to a dramatic decrease in overhydrogenation of olefins.

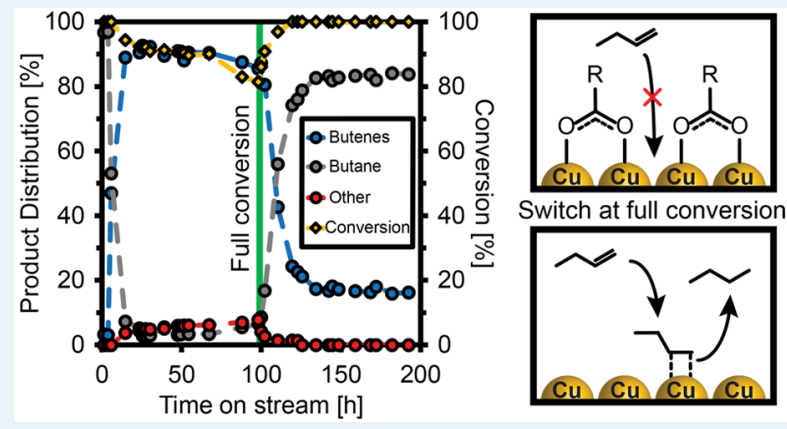

KEYWORDS: olefins, carboxylic acids, copper, silica-alumina, FTIR spectroscopy, selectivity control, biomass

$\mathrm{U}$ tilization of lignocellulosic biomass is becoming increasingly important as we attempt to reduce our dependence on fossil fuels, which are increasingly unsustainable and environmentally problematic. In addition to being used as a source of energy, we are especially reliant on using fossil fuels as our main carbon source for producing carbon-based chemicals and other industrial compounds. Linear olefins, a major bulk chemical and a precursor for, among others, plastics and detergents, are an example of a major product that is derived from petroleum.

Biomass-derived carboxylic acids could be a potential replacement for petroleum in the production of olefins. Carboxylic acids are abundant in nature, natively present in vegetable oil as triglycerides, with more than 350 plants known to contain oil. ${ }^{1}$ Alternatively, lignocellulosic biomass can be converted to carboxylic acids via fermentation, either by using mixtures of simple sugars derived from biomass ${ }^{2}$ or directly fermenting pretreated biomass, ${ }^{3}$ resulting in aliphatic carboxylic acids of 2 to 6 carbon length depending on the fermentation process.

Deoxygenation of aliphatic carboxylic acids to olefins has always been a challenge because of the high stability of the carboxyl group ${ }^{4}$ and the lack of any electron-withdrawing groups (e.g., phenyl groups) or neighboring hydroxyl functionalities ( $\alpha$-hydroxy acids). Aliphatic carboxylic acids are typically weak acids with low dissociation constants $\left(\mathrm{p} K_{\mathrm{a}}\right.$ of hexanoic acid $=4.85)$. Furthermore, dissociated carboxylate anions are resonance-stabilized, thus lowering their reactivity.
The straight chain carbon backbone also limits any reactions to carbon-carbon bond scissions. Thus, the upgrading process must start by targeting the carboxyl group.

Traditional thermal decarboxylation processes usually result in alkanes rather than olefins. ${ }^{5,6}$ Oxidative decarboxylation is a possible route to produce olefins, with the loss of one molecule of carbon dioxide. ${ }^{7-10}$ Decarbonylation of carboxylic acids, where a carbon monoxide and water molecules are removed leaving behind an olefin, has also been demonstrated. ${ }^{11-13}$ However, both routes require the use of a stoichiometric oxidant/reagent to function, which is unsustainable and expensive in the context of bulk chemical production. Environmental friendly oxidants such as $\mathrm{H}_{2} \mathrm{O}_{2}$ or $\mathrm{O}_{2}{ }^{14-17}$ can be used in enzymatic oxidative decarboxylation, but these systems use specifically engineered strains of bacteria and also require additional cofactors.

Rather than decarboxylation/decarbonylation, it is possible to perform hydrogenation. This maintains the carbon chain length, which is especially important in the context of biomass conversion due to the importance of maximizing carbon conversion. ${ }^{18}$ However, care must be taken not to fully hydrogenate the carboxylic acid to an alkane. Platinum ${ }^{19}$ or copper $^{20}$ can be used to hydrogenate carboxylic acids to

Received: August 22, 2018

Revised: October 2, 2018

Published: October 16, 2018 
alcohols. The alcohol formed could then be dehydrated to olefins over an acid catalyst, such as sulfuric acid or silicaalumina.

In this work, our objective was to devise an alternative process to convert dilute streams of carboxylic acids to olefins in one step using tandem hydrogenation/dehydration. By first hydrogenating the carboxylic acids to alcohols, followed by subsequent dehydration to olefins in the same reactor, we can avoid expensive sacrificial reagents as well as preserve the carbon chain length of the substrate. In our investigation of using hexanoic acid and butanoic acid as substrates, we discovered a sudden switch in olefin/alkane selectivity once carboxylic acids were fully consumed. Using several catalyst surface studies, we were able to determine the nature of this selectivity switch. Finally, we demonstrate the application of this process to butanoic acid that was directly produced from pretreated beech wood in a consolidated bioprocess.

Performing tandem hydrogenation/dehydration reactions on carboxylic acids in one process required a bifunctional catalyst that had both hydrogenation and alcohol dehydration properties. We selected $\mathrm{Cu}$ supported on commercial silicaalumina $(\mathrm{Cu} / \mathrm{Si}-\mathrm{Al})$, with the rationale that $\mathrm{Cu}$ could act as a mild hydrogenation catalyst and the acid sites on silicaalumina could perform dehydration reactions. Partial hydrogenation of hexanoic acid resulted in 1-hexanol, which could partially esterify with unreacted hexanoic acid to form hexyl hexanoate (Scheme 1). This is an undesired side reaction that

Scheme 1. Proposed Reaction Pathway for the Tandem Hydrogenation/Dehydration of Hexanoic Acid. ${ }^{a}$

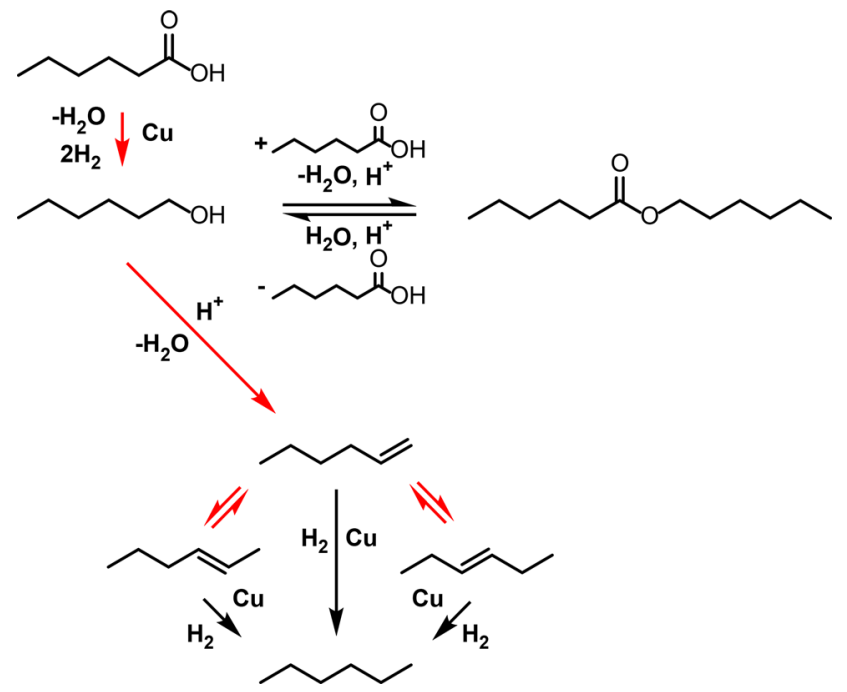

${ }^{a}$ The main pathways are highlighted in red.

occurs mainly on Brønsted acid sites, but it is reversible. ${ }^{21}$ As an intermediate, 1-hexanol then underwent dehydration to form hexenes. As a primary alcohol, the reaction likely occurred through the E2 mechanism, resulting in 1-hexene. However, at high temperatures and acidic conditions, doublebond migration was favorable, resulting in formation of internal hexenes. Finally, undesired overhydrogenation of the hexenes to hexane also occurred, and, as discussed below, was highly dependent on reaction conditions.

We carried out the tandem hydrogenation/dehydration of hexanoic acid in an upflow fixed-bed reactor at $210{ }^{\circ} \mathrm{C}$ and 5 bar $\mathrm{H}_{2}$, using $\mathrm{Cu} / \mathrm{Si}-\mathrm{Al}$ with a copper loading of 6 wt $\%$ and a metal dispersion of 5\%. At first, hexane was the major product indicating almost complete overhydrogenation of olefins (Figure 1A), likely due to an abundance of hydrogen present
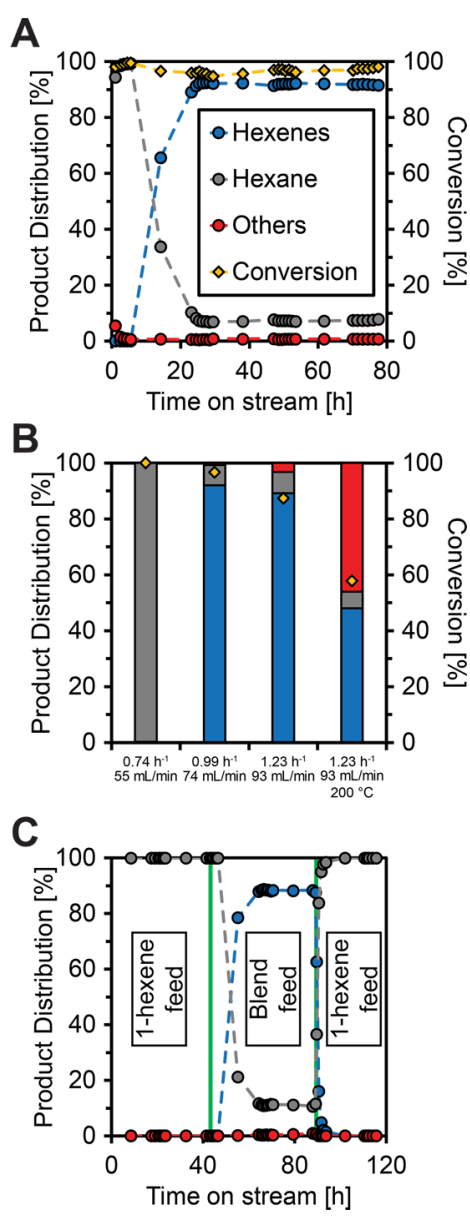

Figure 1. (A) Conversion and molar product distribution of hexanoic acid tandem hydrogenation/dehydration as a function of time on stream (WHSV $=0.99 \mathrm{~h}^{-1}, \mathrm{H}_{2}$ flow $=74 \mathrm{~mL} / \mathrm{min}, T=210^{\circ} \mathrm{C}, P=5$ bar and feed $=2$ wt \% hexanoic acid in isooctane). (B) Average steady state conversion and molar product distribution of hexanoic acid tandem hydrogenation/dehydration at different WHSV $\left(T=210^{\circ} \mathrm{C}\right.$, $P=5$ bar and feed $=2 \mathrm{wt} \%$ hexanoic acid in isooctane). (C) Molar product distribution of an intermediate products study as function of time on stream $\left(\right.$ WHSV $=0.99 \mathrm{~h}^{-1}, \mathrm{H}_{2}$ flow $=74 \mathrm{~mL} / \mathrm{min}, \mathrm{T}=210$ ${ }^{\circ} \mathrm{C}, P=5$ bar and initial feed $=2 \mathrm{wt} \% 1$-hexene in isooctane). Green lines represent a feed switch to either 2 wt \% 1-hexene/2 wt \% hexanoic acid in isooctane or $2 \mathrm{wt} \% 1$-hexene in isooctane. The legend for Figure 1B,C can be found in Figure 1A. The WHSV is calculated based on the total liquid feed.

on the fresh catalyst bed. After this initial induction period, the reaction stabilized and selectivity to hexenes increased significantly until they were the major product. At a weight hourly space velocity (WHSV) of $0.99 \mathrm{~h}^{-1}$, we obtained $96.7 \%$ conversion and a molar product distribution of $92.0 \%$ hexenes and $7.3 \%$ hexane at steady state. The hexenes consisted of predominantly 2-hexene and 3-hexene $(95 \mathrm{~mol} \%$ of total olefins), indicating a high degree of double bond migration after the dehydration step. Skeletal rearrangement was not significant ( $3 \mathrm{~mol} \%$ of total olefins). There was a slight overhydrogenation of the olefins to hexane under those reaction conditions, along with a small production of hexyl hexanoate. The conversion and product distribution were 
constant over $80 \mathrm{~h}$ on stream ( $0.8 \mathrm{~g}$ hexenes produced/g catalyst over $80 \mathrm{~h}$ in this experiment), attesting good catalyst stability. When using a higher concentration (10 wt \%) of hexanoic acid as feed (and adjusting the flow rate and WHSV to yield a similar ratio of incoming hexanoic acid to catalyst weight), a comparable performance to the 2 wt \% feed was achieved, demonstrating that a high dilution was not necessary to obtain these results (Figure S1).

Increasing the WHSV to $1.23 \mathrm{~h}^{-1}$ lowered the conversion to $87.5 \%$ (Figure 1B). At these conditions, we also detected a higher amount of hexyl hexanoate in the product stream, showing that esterification was a competing side reaction when significant amounts of hexanoic acid were present. In the previous case of $96.7 \%$ conversion, the amount of unreacted hexanoic acid was low enough that most of the 1-hexanol formed proceeded to dehydrate to hexenes. We lowered the temperature of the reaction to $200{ }^{\circ} \mathrm{C}$, thereby further lowering the conversion to $57.8 \%$. At this conversion, large quantities of hexyl hexanoate were formed. The proportion of hexane formed was similar compared to previous conditions, implying that the slight overhydrogenation of olefins was independent of the conversion and WHSV.

Interestingly, we observed a brusque selectivity switch to 99.8\% hexane at full conversion, after a decrease in WHSV from $0.99 \mathrm{~h}^{-1}$ to $0.74 \mathrm{~h}^{-1}$ (while maintaining the hydrogen flow to feed flow ratio constant). This contrasted with other reaction conditions where the proportion of overhydrogenation was constant.

We hypothesize that the presence of a small amount of hexanoic acid on the catalyst surface inhibited overhydrogenation of the hexenes to hexane. To ascertain the nature of this selectivity switch, we performed a study of intermediate products at WHSV $=0.99 \mathrm{~h}^{-1}$ (Figure $1 \mathrm{C}$ ). By initially flowing only 1-hexene over the catalyst bed, complete overhydrogenation was observed. Changing the feed to a blend of hexanoic acid and 1-hexene switched the selectivity to a similar product distribution as the original hexanoic acid feed (88.3\% hexenes and $11.2 \%$ hexanes) at those conditions. As the reaction temperature and pressure were constant, this switch could not have happened because of changes in vapor pressure or an unexpected phase change. We rationalized that this phenomenon occurred as a result of the interaction of the reaction species on the surface of the catalyst in the presence/absence of hexanoic acid.

The initial induction period of the reaction (shown for a WHSV of $0.99 \mathrm{~h}^{-1}$ in Figure 1A) was also used to probe this phenomenon. When conducting the experiment under Ar flow for the first $24 \mathrm{~h}$ (instead of $\mathrm{H}_{2}$ ) and subsequently switching to $\mathrm{H}_{2}$ flow, a high selectivity of hexenes was achieved immediately (Figure S2A). However, this resulted in some deactivation of the catalyst. When performing a similar experiment using an $\mathrm{Ar}$ flow for $1 \mathrm{~h}$ (Figure S2B), the deactivation was not as significant $(83.4 \%$ vs $96.7 \%$ conversion), and a shorter induction period was observed compared to constant $\mathrm{H}_{2}$ flow ( $7 \mathrm{~h}$ vs $24 \mathrm{~h}$ ). These results showed that $\mathrm{H}_{2}$ was important in maintaining catalyst stability and confirmed that the initial induction period with high alkane selectivity was due to an abundance of hydrogen present on the surface of a fresh catalyst bed. Furthermore, preadsorbing the catalyst with hexanoic acid mitigated the initial overhydrogenation of the hexenes to hexane, albeit with severe catalyst deactivation under an $\mathrm{Ar}$ atmosphere, further confirming the important effect of adsorbed carboxylic acids on product selectivity.
To further explore the interaction of the reacting species with the catalyst surface, a temperature-programmed desorption (TPD) of 1-hexene on the catalyst surface was performed to determine its adsorbed quantity on the catalyst (Figure 2A).

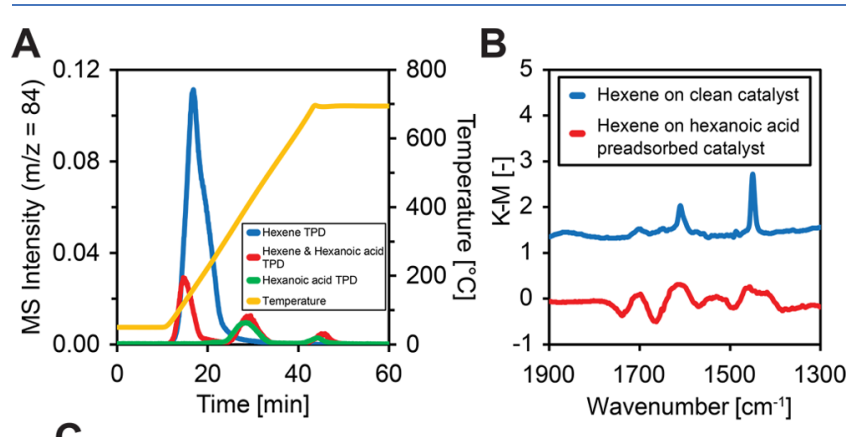

C

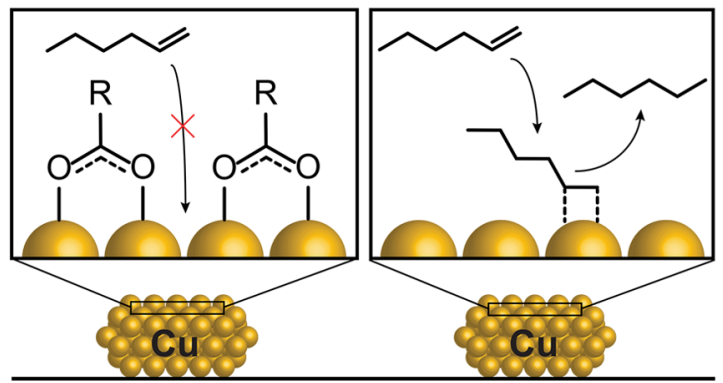

Figure 2. (A) Temperature-programmed desorption (TPD) of different reaction species on the catalyst while using the MS to track mass 84 (molecular ion peak of 1-hexene). (B) Subtracted FTIR spectra of different molecules adsorbed on the surface of the catalyst at $25{ }^{\circ} \mathrm{C}$. For both spectra, the displayed spectrum is the difference between the spectra obtained before and after 1-hexene adsorption (and after hexanoic acid preadsorption for the preadsorbed catalyst). K-M stands for Kubelka-Munk. Figure S3 shows the subtracted FTIR spectra of 1-hexene adsorbed on the surface of $\mathrm{KBr}$ at $25{ }^{\circ} \mathrm{C}$, which had no signal. (C) Illustration depicting the accessibility of hydrogenation sites in the presence/absence of adsorbed hexanoic acid. The adsorption mode of carboxylic acids on copper is still debated in the literature, ${ }^{22-24}$ but one mode of adsorption is shown here for illustrative purposes.

On a clean catalyst surface, we observed $234 \mu \mathrm{mol} / \mathrm{g}$ of 1 hexene adsorbed on the surface of the catalyst. In contrast, by preadsorbing hexanoic acid on the catalyst (which, we estimate led to roughly the same amount of acid adsorbed as 1hexene-measured as $285 \mu \mathrm{mol} / \mathrm{g}$ with acetic acid, see Section 5 of the SI), the amount of 1 -hexene adsorbed decreased to 10 $\mu \mathrm{mol} / \mathrm{g}$. TPD of just hexanoic acid confirmed the attribution of the 2 desorption peaks at $\sim 400{ }^{\circ} \mathrm{C}$ and $\sim 700{ }^{\circ} \mathrm{C}$ to the desorption and degradation of hexanoic acid itself (the fragmentation pattern of hexanoic acid contains mass 84), and not to more strongly adsorbed 1-hexene in the presence of hexanoic acid. These findings suggest that the presence of hexanoic acid severely limits the adsorption of 1-hexene, thus decreasing overhydrogenation.

We further confirmed this hypothesis by Fourier-transform infrared (FTIR) spectroscopy. 1-Hexene adsorbed on a clean catalyst exhibited two adsorption bands at 1608 and 1449 $\mathrm{cm}^{-1}$, attributed to the $\mathrm{C}=\mathrm{C}$ stretching mode and the $=\mathrm{CH}_{2}$ scissoring mode, respectively (Figure $2 \mathrm{~B}$ ). The slight red-shift of the $\mathrm{C}=\mathrm{C}$ band is attributed to $\mathrm{C}=\mathrm{C}$ bond weakening upon adsorption on the catalyst. ${ }^{25}$ Conversely, the characteristic bands of 1-hexene were not observed upon 1-hexene 

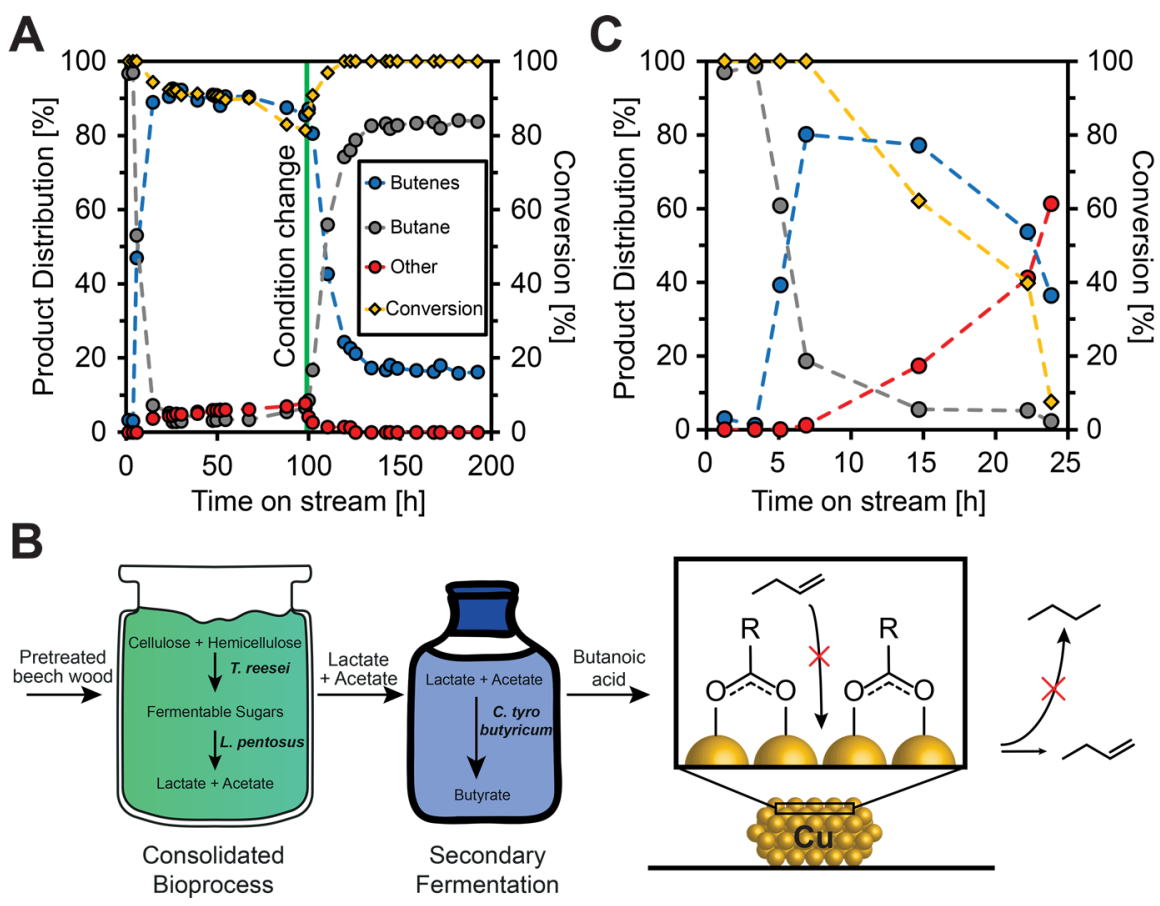

Figure 3. (A) Conversion and molar product distribution of butanoic acid tandem hydrogenation/dehydration as a function of time on stream (WHSV $=0.49 \mathrm{~h}^{-1}, \mathrm{H}_{2}$ flow $=38 \mathrm{~mL} / \mathrm{min}, T=210{ }^{\circ} \mathrm{C}, P=5 \mathrm{bar}$, and feed $=2 \mathrm{wt} \%$ butanoic acid in isooctane). The green line represents a condition change to WHSV $=0.25 \mathrm{~h}^{-1}$ and $\mathrm{H}_{2}$ flow $=19 \mathrm{~mL} / \mathrm{min}$. (B) Illustration of the consolidated bioprocessing of steam-exploded beech wood to butanoic acid, followed by tandem hydrogenation/dehydration to form butenes. The adsorption mode of carboxylic acids on copper is still debated in the literature, ${ }^{22-24}$ but one mode of adsorption is shown here for illustrative purposes. (C) Conversion and molar product distribution of biomass-derived butanoic acid tandem hydrogenation/dehydration as a function of time on stream (WHSV $=0.49 \mathrm{~h}^{-1}, \mathrm{H}_{2}$ flow $=38 \mathrm{~mL} / \mathrm{min} \mathrm{T}$ $=210{ }^{\circ} \mathrm{C}, P=5 \mathrm{bar}$ and feed $=2 \mathrm{wt} \%$ biomass-derived butanoic acid in isooctane). The legend for Figure 3C can be found in Figure 3A. The WHSV is calculated on the basis of the total liquid feed.

adsorption after preadsorption of hexanoic acid on the catalyst. The absence of 1-hexene signals further indicated that hexanoic acid prevented 1-hexene from bonding and being overhydrogenated to hexane by occupying the hydrogenation sites of the catalyst (Figure 2C).

This phenomenon can be extended to other carboxylic acids. We performed tandem hydrogenation/dehydration on butanoic acid and obtained an average steady-state molar product distribution of $90.9 \%$ butenes, $3.7 \%$ butane, and $5.4 \%$ others at a conversion of $90.9 \%$ (Figure $3 \mathrm{~A}$ ). The increased amount of esters can be due to the lower conversion of $90.9 \%$ compared with the $96.7 \%$ obtained with our previous experiments using hexanoic acid. Nonetheless, by pushing the conversion to completion, we observed a similar selectivity switch, although there was a higher proportion of butenes (17.0\%) to butane (83.0\%) compared with hexanoic acid (99.8\% hexane). The feed flow rate had to be reduced for butanoic acid, as there was a higher molar concentration in the feed due to the lower molar mass of butanoic acid compared with hexanoic acid.

In order to demonstrate this concept for real biomassderived products, we used our process on butanoic acid produced with a novel consolidated bioprocessing method that produced the carboxylic acid directly from steam-exploded beech wood (Figure 3B). Tandem hydrogenation/dehydration of biomass-derived butanoic acid initially proceeded similarly to commercial butanoic acid feed, with a peak molar product distribution of $80 \%$ butenes (Figure $3 \mathrm{C}$ ). However, the catalyst suffered from significant deactivation after $8 \mathrm{~h}$ on stream. It is likely that the extraction process resulted in slight impurities that adsorbed on the catalyst surface, as the reaction proceeded smoothly with the commercial butanoic acid feed. Nevertheless, this shows that the use of biomass-derived carboxylic acids was possible, although optimization of the extraction process is still required.

In summary, we demonstrate that biomass-derived streams of carboxylic acids can be converted into mixtures of olefins in a single step. Using $\mathrm{Cu} / \mathrm{SiO}_{2}-\mathrm{Al}_{2} \mathrm{O}_{3},>90 \%$ olefin selectivity was achieved at close to $99 \%$ conversion. At full conversion, an abrupt selectivity switch occurred, changing the product distribution from predominantly olefins to almost exclusively alkanes. Through TPD and FTIR catalyst surface studies, we proposed that the observed selectivity switch occurred because of the presence of a small amount of carboxylic acids on the catalyst surface, which prevented binding and subsequent overhydrogenation of the olefins. We propose that the inhibition of catalyst active sites using carboxylic acids could also be applied to hydrogenation reactions using other substrates, where selective preservation of double bond functionalities is required. By doing so, we could possibly influence the product distributions of other types of catalytic reactions by controlling the presence of carboxylic acids in the reaction media. Differences in catalyst performance when processing commercial compounds versus real biomass-derived feed in biomass upgrading reactions could also be explained; especially given the ubiquity of carboxylic acid impurities in biomass-derived mixtures. An improved understanding of the influence of these functionalities on catalytic reactions will be important in developing future biorefining processes. Therefore, this phenomenon can both help better understand the 
catalytic processing of biomass and open new avenues for selectivity control during catalytic reactions.

\section{ASSOCIATED CONTENT}

\section{S Supporting Information}

The Supporting Information is available free of charge on the ACS Publications website at DOI: 10.1021/acscatal.8b03370.

Chemicals and materials, experimental procedure for catalyst preparation, catalyst characterization, catalytic testing, TPD and FTIR experiments, production of butanoic acid from beech wood, and extraction of butanoic acid (PDF)

\section{AUTHOR INFORMATION}

\section{Corresponding Author}

*E-mail: jeremy.luterbacher@epfl.ch.

\section{ORCID}

Jher Hau Yeap: 0000-0002-4954-4688

Jeremy S. Luterbacher: 0000-0002-0967-0583

Notes

The authors declare no competing financial interest.

\section{ACKNOWLEDGMENTS}

This work was supported by the Swiss National Science Foundation (SNSF) under the National Research Program 70: Energy Turnaround program (nb: 407040_153866), and through the SNSF Assistant Professor Energy grant PYAPP2 15428. This work was also supported by the Swiss Competence Center for Bioenergy Research (SCCER-BIOSWEET) through the Swiss Commission for Technology and Innovation grant KTI.2014.0116 and by EPFL.

\section{REFERENCES}

(1) Huber, G. W.; Corma, A. Synergies between Bio- and Oil Refineries for the Production of Fuels from Biomass. Angew. Chem., Int. Ed. 2007, 46, 7184-7201.

(2) Steen, E. J.; Kang, Y.; Bokinsky, G.; Hu, Z.; Schirmer, A.; McClure, A.; del Cardayre, S. B.; Keasling, J. D. Microbial Production of Fatty-Acid-Derived Fuels and Chemicals from Plant Biomass. Nature 2010, 463, 559-562.

(3) Shahab, R. L.; Luterbacher, J. S.; Brethauer, S.; Studer, M. H. Consolidated Bioprocessing of Lignocellulosic Biomass to Lactic Acid by a Synthetic Fungal-Bacterial Consortium. Biotechnol. Bioeng. 2018, $115,1207-1215$.

(4) Pritchard, J.; Filonenko, G. A.; van Putten, R.; Hensen, E. J. M.; Pidko, E. A. Heterogeneous and Homogeneous Catalysis for the Hydrogenation of Carboxylic Acid Derivatives: History, Advances and Future Directions. Chem. Soc. Rev. 2015, 44, 3808-3833.

(5) Mäki-Arvela, P.; Snåre, M.; Eränen, K.; Myllyoja, J.; Murzin, D. Y. Continuous Decarboxylation of Lauric Acid over Pd/C Catalyst. Fuel 2008, 87, 3543-3549.

(6) Snåre, M.; Kubičková, I.; Mäki-Arvela, P.; Eränen, K.; Murzin, D. Y. Heterogeneous Catalytic Deoxygenation of Stearic Acid for Production of Biodiesel. Ind. Eng. Chem. Res. 2006, 45, 5708-5715.

(7) Bacha, J. D.; Kochi, J. K. Alkenes from Acids by Oxidative Decarboxylation. Tetrahedron 1968, 24, 2215-2226.

(8) Anderson, J. M.; Kochi, J. K. Silver(I)-Catalyzed Oxidative Decarboxylation of Acids by Peroxydisulfate. Role of Silver(II). J. Am. Chem. Soc. 1970, 92, 1651-1659.

(9) Anderson, J. M.; Kochi, J. K. Silver(II) Complexes in Oxidative Decarboxylation of Acids. J. Org. Chem. 1970, 35, 986-989.

(10) Anderson, J. M.; Kochi, J. K. Manganese(III) Complexes in Oxidative Decarboxylation of Acids. J. Am. Chem. Soc. 1970, 92, $2450-2460$.
(11) Foglia, T. A.; Barr, P. A. Decarbonylation Dehydration of Fatty Acids to Alkenes in the Presence of Transition Metal Complexes. J. Am. Oil Chem. Soc. 1976, 53, 737-741.

(12) Maetani, S.; Fukuyama, T.; Suzuki, N.; Ishihara, D.; Ryu, I. Efficient Iridium-Catalyzed Decarbonylation Reaction of Aliphatic Carboxylic Acids Leading to Internal or Terminal Alkenes. Organometallics 2011, 30, 1389-1394.

(13) Maetani, S.; Fukuyama, T.; Suzuki, N.; Ishihara, D.; Ryu, I. Iron-Catalyzed Decarbonylation Reaction of Aliphatic Carboxylic Acids Leading to $\alpha$-Olefins. Chem. Commun. 2012, 48, 2552-2554.

(14) Grant, J. L.; Hsieh, C. H.; Makris, T. M. Decarboxylation of Fatty Acids to Terminal Alkenes by Cytochrome P450 Compound I. J. Am. Chem. Soc. 2015, 137, 4940-4943.

(15) Rui, Z.; Harris, N. C.; Zhu, X.; Huang, W.; Zhang, W. Discovery of a Family of Desaturase-Like Enzymes for 1-Alkene Biosynthesis. ACS Catal. 2015, 5, 7091-7094.

(16) Rui, Z.; Li, X.; Zhu, X.; Liu, J.; Domigan, B.; Barr, I.; Cate, J. H. D.; Zhang, W. Microbial Biosynthesis of Medium-Chain 1-Alkenes by a Nonheme Iron Oxidase. Proc. Natl. Acad. Sci. U. S. A. 2014, 111, 18237-18242.

(17) Dennig, A.; Kuhn, M.; Tassoti, S.; Thiessenhusen, A.; Gilch, S.; Bülter, T.; Haas, T.; Hall, M.; Faber, K. Oxidative Decarboxylation of Short-Chain Fatty Acids to 1-Alkenes. Angew. Chem., Int. Ed. 2015, 54, 8819-8822.

(18) Agrawal, R.; Singh, N. R.; Ribeiro, F. H.; Delgass, W. N. Sustainable Fuel for the Transportation Sector. Proc. Natl. Acad. Sci. U. S. A. 2007, 104, 4828-4833.

(19) Manyar, H. G.; Paun, C.; Pilus, R.; Rooney, D. W.; Thompson, J. M.; Hardacre, C. Highly Selective and Efficient Hydrogenation of Carboxylic Acids to Alcohols Using Titania Supported Pt Catalysts. Chem. Commun. 2010, 46, 6279-6281.

(20) Cortright, R. D.; Sanchez-Castillo, M.; Dumesic, J. A. Conversion of Biomass to 1,2-Propanediol by Selective Catalytic Hydrogenation of Lactic Acid over Silica-Supported Copper. Appl. Catal., B 2002, 39, 353-359.

(21) Shi, W.; Zhao, J.; Yuan, X.; Wang, S.; Wang, X.; Huo, M. Effects of Brønsted and Lewis Acidities on Catalytic Activity of Heteropolyacids in Transesterification and Esterification Reactions. Chem. Eng. Technol. 2012, 35, 347-352.

(22) Tao, Y. T. Structural Comparison of Self-Assembled Monolayers of n-Alkanoic Acids on the Surfaces of Silver, Copper, and Aluminum. J. Am. Chem. Soc. 1993, 115, 4350-4358.

(23) Wühn, M.; Weckesser, J.; Wöll, C. Bonding and Orientational Ordering of Long-Chain Carboxylic Acids on $\mathrm{Cu}(111)$ : Investigations Using X-Ray Absorption Spectroscopy. Langmuir 2001, 17, $7605-7612$.

(24) Woodruff, D. P.; McConville, C. F.; Kilcoyne, A. L. D.; Lindner, T.; Somers, J.; Surman, M.; Paolucci, G.; Bradshaw, A. M. The Structure of the Formate Species on Copper Surfaces: New Photoelectron Diffraction Results and Sexafs Data Reassessed. Surf. Sci. 1988, 201, 228-244.

(25) Datka, J.; Kukulska-Zając, E. IR Studies of the Activation of $\mathrm{C}=\mathrm{C}$ Bond in Alkenes by $\mathrm{Cu}^{+}$Ions in Zeolites. J. Phys. Chem. B 2004, 108, 17760-17766. 